\section{January 2017}

\section{What are our priorities?}

The Great Plains Center for Agricultural Health (GPCAH) is one of 11 agricultural education, research and prevention centers funded by the National Institute for Occupational Safety and Health. GPCAH has just completed one cooperative agreement period (2011-2016) and is entering a new period (20162021) with new research projects. GPCAH's goal is to reduce the burden of workplace injury and illness among Midwest farmers. Current priorities are to:

- Reduce traumatic injuries from roadway crashes with agricultural equipment

- Reduce exposures to air contaminants for livestock workers

- Reduce musculoskeletal disorders among farmworkers

\section{What do we do?}

- Conduct research and surveillance to identify sources of injury and illness.

- Disseminate practical tools to farmers, their advocates, and health care providers to improve awareness and adoption of best-practices in safety and health.

\section{What have we accomplished?}

- Identified that rollovers (25\%) and falls (20\%) are the most frequent source of traumatic injuries among farmers, particularly older than 45 years, and disseminated regional surveillance findings to regional public health partners.

- Identified risk factors associated with on-theroad crashes of agricultural equipment. Created a safety outreach campaign with radio public service announcements and distributed American Society of Agricultural and Biological Engineers -standard lighting and marking kits to over 200 farmers.

- Found that new vented heaters can significantly reduce $\mathrm{CO}_{2}$ concentrations in swine production buildings, which could improve both livestock and worker health.

- Identified that air filtration units could significantly lower dust concentrations in farrowing periences to support classroom learning.
- Develop evidence-based safety recommendations to farmers, manufacturers, commodity groups, policy makers, and other stakeholders.

- Lead national training for the next generation of agricultural safety and health professionals.
The Great Plains Center for Agricultural Health (GPCAH) conducts research and provides education and outreach to prevent work-related injuries and illnesses among agricultural communities. This snapshot shows recent accomplishments and upcoming work

GPCAH, located in lowa City, IA, serves nine Midwestern states
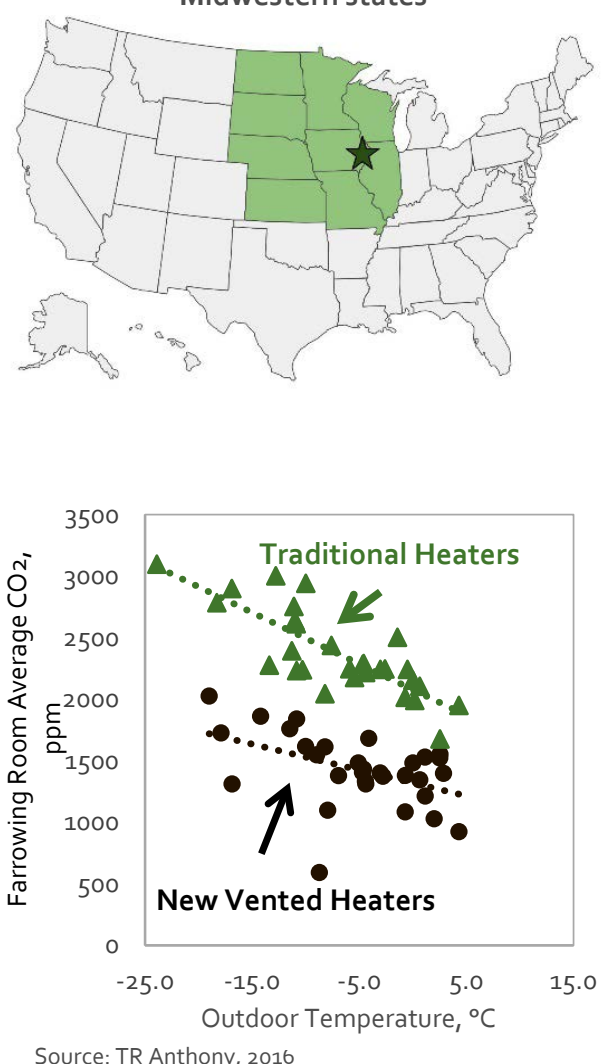

- Updated the Agricultural Medicine Core Course, adding hands-on demonstrations and field ex-

- Funded an educational pilot project in South Dakota to educate members in six Hutterite colonies on the importance of farm safety prior to harvest season, leading to more than $50 \%$ reduction in agriculture trauma-related incidents at a regional medical center.

\section{What's next?}

- Observe and understand motor vehicle driver behavior near farm equipment. Develop a community intervention that will reduce roadway crashes with farm equipment.

- Improve injury surveillance among agricultural workers by partnering with a national insurance company
- Implement air quality improvement technologies in large scale livestock production operations leading to better health and greater productivity.

- Work with regional advisors, producer partners, and other Ag Centers to disseminate research findings and interventions on emerging and persistent health and safety hazards.
Where farmers plan to install new equipment marking kits to reduce crash risk

$0 \% \quad 10 \% \quad 20 \% \quad 30 \% \quad 40 \%$

\begin{tabular}{l}
\hline Grain cart \\
\hline Tractors \\
\hline Trailer (crop and/or livestock) \\
\hline Other \\
\hline Hay equipment \\
Sprayer \\
Combine \\
Manure spreader \\
Source: GPCAH program records \\
"Other" includes skid loader, mowers, grinder/mixers, \\
ammonia tank, and flat bed trailers.
\end{tabular}

